\title{
Playing time between senior rugby players of different ethnic groups across all levels of South African rugby, 2007- 2011
}

\author{
Jacques du Toit, Justin Durandt, Jonathan Joshua, Herman Masimla, Mike Lambert \\ Discovery High Performance Centre, Sports Science Institute of South Africa, and MRC/UCT Research Unit for Exercise Science and Sports Medicine, Faculty of \\ Health Sciences, University of Cape Town \\ Jacques du Toit, BA (Hons) Biokinetics \\ Justin Durandt, BSc (Med Hon) Exercise Science (Biokinetics) \\ Jonathan Joshua, BSc (Med Hon) Exercise Science (Biokinetics) \\ Mike Lambert, PhD
}

South African Rugby Union

Herman Masimla, BA, HDE

Corresponding author: Jacques du Toit (jdtoit@ssisa.com)

Background. The South African Rugby Union (SARU) has had a continual challenge to make the game representative of players of all ethnic groups at all levels of play. In response to this challenge SARU has implemented several programmes designed to accelerate the development of players from previously disadvantaged areas with the goal of making the game more representative. However, the success of these programmes to transform the player profile at different levels of rugby cannot be evaluated because the players representing different ethnic groups have not been quantified in a systematic way.

Objectives. To quantify the number and playing time of South African professional players (Vodacom, Currie Cup, Super Rugby and Springboks) from different ethnic groups from 2007 to 2011 to determine whether there are any changes in the profile of the players over this period.

Methods. Playing time was recorded for all players in sanctioned matches. Players were divided into the ethnic classifications used by SARU (i.e. white, coloured and black).

Results. At all levels of competition there were proportionally more white players, followed by coloured players and then black players. This pattern did not change from 2007 to 2011. Based on the ratio of number of players $v$. playing time, the white players played more time than expected at the Springbok level, whereas the black players played less than expected for the number of players from 2007 to 2011. At the Vodacom level the white players played more than expected in 2007 and 2008 and played less than expected in 2010 and 2011, whereas the black players played more than expected in 2010 and the coloured players played more than expected at the 2011 tournament. The Super Rugby tournament had the most consistency between players and expected playing time for the different ethnic groups.

Conclusions. Despite the effort to support players from disadvantaged backgrounds since 1998 with facilitative programmes and selection targets, the professional game is still dominated by white players at all levels.

S Afr J SM 2012;24(3):81-86. DOI:10.7196/SAJSM.327

\section{Introduction}

Following the formation of a single body to govern rugby in South Africa in 1992, the South African Rugby Union (SARU) has had a continual challenge to make the game fully representative at all levels, particularly since most representative teams at all levels were dominated by white players. ${ }^{1,2}$ Politicians have accused SARU of being resistant to change despite SARU's attempt to transform the game by launching several programmes designed to promote the development of black and coloured players from previously disadvantaged areas. ${ }^{3}$ For example, the 'Nike All Stars' programme ran from 1999 to 2002 and focused on the talent identification of youth (12 - 15 years). The players identified by this programme were invited to attend various provincial trials and training camps spanning the 4-year period of the programme. For many players these camps were their first exposure to the demands and expectations of a professional athlete. Players were exposed to physiological testing, nutritional advice, life skills and technical rugby coaching. The 'Spoornet Rugby Excellence' programme had a similar structure to the 'Nike All Stars' programme and ran for a 5-year period from 1998 to 2002. This programme focused on players of all ages, including senior players. Players from across the country were identified and invited to various camps that focused on equipping players with the skills needed to play rugby at a higher level. The players had a full medical evaluation, followed by any appropriate medical intervention they needed. Their physiological characteristics were profiled and players received customised training programmes and access to strength-training facilities. Training camps were held throughout the year to facilitate the continual development of the players participating in the programme. In addition players received personalised interventions including accommodation, transport and educational grants where required. The programme aimed to be comprehensive and facilitate the development of the players in the senior ranks.

In 2002 SARU introduced high-performance workshops at the U18 Craven week. A study at this Craven week showed that black and coloured players weighed about $8 \mathrm{~kg}$ less than their white counterparts. ${ }^{4}$ This study also showed that most of these players did not have access to weight training equipment. In response to these findings SARU and the Sports Science Institute of South Africa 
developed and launched the Mobile Team Training System (MTTS) in 2003. The MTTS is a shipping container that has been modified and refurbished with high-quality strength-training equipment, so that an entire team can train simultaneously. The MTTS container can be transported to remote areas within the country and provide highquality training facilities to the teams that previously did not have access to equipment. By the middle of 2011, SARU had distributed 32 MTTS units across the country. Coinciding with the delivery of the MTTS to a region, SARU organises a strength-training workshop for all coaches and trainers in the region and also provides on-going monitoring and support.

In 2003 the Green Squads were also introduced with the goal of developing talent. This was a broad-based talent identification programme designed to serve the needs of the provinces and national teams. The Green Squad comprised five age groups, each with \pm 100 players, representing players in the under-16, -17, -18, -19 and -20 age groups. Players were selected, based on their rugby skills, by a national panel of selectors. National scouts also provided input for selection. Once the players in each of the age groups were selected, they were subjected to 3 assessment sessions for the year. These sessions consisted of physical tests, skills tests and nutritional assessments. Players were given feedback on their performance in each of the 3 assessment areas.

In 2006 the high-performance workshops were expanded to the Academy Week (national U18 week) and Grant Khomo Week (national U16 Week). In 2007 SARU launched the Elite Squad project, which replaced the old Green Squads. SARU had found that players from disadvantaged areas were still experiencing challenges in terms of their nutrition, supplements and conditioning and the aim of this new programme was to bridge the gap between the age group players in the country by providing testing equipment, supplements and money for all the unions. This programme ran for 3 years.

In addition to these programmes SARU has placed further emphasis on transformation by having quotas for 'players of colour' (which is a SARU euphemism for black and coloured players) at both junior and senior levels. For example, in the 2010 Craven Week (national $\mathrm{U} 18$ week) teams were to be selected with a ratio of 13 white players to 9 players of colour, while the Academy Week and Grant Khomo Week teams were to be selected with a ratio of 11 white players to 11 players of colour. ${ }^{5}$ Most recently, the 2011 Varsity Cup (University Rugby Competition) had regulations which required for the playing squad of 23 players to contain 5 players of colour while 3 players of colour had to be on the field at all times. ${ }^{6}$

Despite the various SARU programmes which have been established to address transformation, and the implementation of quota policies in selection, there is still concern that the effects of these attempts to transform the game are not filtering through to the higher senior levels of the game. These concerns cannot be quantified because there are no hard data against which the effects of these programmes can be measured. This is coupled with the confusion about having a measurable definition of 'transformation'. A meeting between all provincial presidents in 2006 highlighted the shortcomings of defining transformation through the simplistic view of just counting heads of players. ${ }^{7}$ We propose that an alternative and better way of defining and monitoring transformation is to report the total playing time of players in a season. This approach would circumvent the problem of having 'token' players in the team who were selected to merely make up numbers so the team could conform to the required demographics.
Such players would not contribute much to the playing team and mask the transformation of players. This approach of quantifying transformation programmes is in alignment with the National Sports Plan (p. $56-57)^{8}$ with which all sporting governing bodies are expected to comply and the Targeted Performance Dimensions contained in the Transformation Charter for South African Sport (Appendix A - Dimension 3, p. 44). ${ }^{9}$

Therefore the aim of the study was to quantify playing time of the senior players at different levels (Vodacom, Currie Cup, Super Rugby and Springboks) from 2007 to 2011 to determine firstly whether there are differences between the proportions of white, coloured and black players, and secondly whether there have been changes in these values over this period. It would have been helpful to include national and provincial age group teams. However, these data were not available, hence the analysis was limited to senior players.

\section{Methods}

The playing time of all professional rugby union players in South Africa during the 2007, 2008, 2009, 2010 and 2011 seasons was tabulated. Playing time was defined as the total minutes played by a professional rugby union player during a sanctioned competitive match excluding friendly matches. Therefore playing time was recorded for all players involved in Springbok test matches, Super Rugby competitive matches, Absa Currie Cup matches and Vodacom Cup matches during these five seasons. The players were divided into racial populations based on the same classification system used by SARU, i.e. white, black or coloured. The player's racial information was obtained through either the SARU official website (www.sarugby.co.za) or by directly contacting the union that the player was contracted to.

The playing time of each individual player for that match was obtained on the SARU official website. The playing time was determined by the total time the player spent on the field of play. Red and yellow cards, tactical substitutions and blood injury substitutions were considered in the calculations. If a player was part of the 22 man playing squad, but did not play during the match, he was not credited with any playing time. The maximum playing time a player could accumulate for a single match was limited to 80 minutes. In the event of a knockout match resulting in a tie, additional halves would be played and this additional time would be added onto the overall playing time. The data for each match were checked for arithmetical accuracy (i.e. the total time for each match had to equal 1200 minutes per team unless a player received a yellow, red card or additional halves being played).

\section{Results}

The total number of players per season in the different competitive levels for the seasons 2007 - 2011 is shown in Table 1. In all cases (competition v. year) there were proportionally more white players, followed by coloured and black players. There were no noteworthy changes in representation (i.e. player number) over the 5 years. Table 2 shows the total playing time for the season for each ethnic group (2007 - 2011). Similarly, the total playing time of the white players was higher than that of the coloured and black players and there were no obvious trends over the years.

In Fig. 1 the total number of players (expressed as a percentage of the overall total on the $\mathrm{x}$ axis) is plotted against the total playing time (expressed as a percentage of the total playing time on the $y$ axis) for 2007 - 2011. When the data point lies on the line of unity it may be 
Table 1. The number and (\%) of white, coloured and black rugby players for the Springboks, Super Rugby, Currie Cup and Vodacom teams, 2007 - 2011

\begin{tabular}{lllllll}
\hline & & $\mathbf{2 0 0 7}$ & $\mathbf{2 0 0 8}$ & $\mathbf{2 0 0 9}$ & $\mathbf{2 0 1 0}$ & $\mathbf{2 0 1 1}$ \\
\hline Springboks & Whites & $36(77 \%)$ & $26(65 \%)$ & $32(67 \%)$ & $35(70 \%)$ & $31(72 \%)$ \\
& Coloured & $9(19 \%)$ & $7(18 \%)$ & $11(23 \%)$ & $10(20 \%)$ & $8(19 \%)$ \\
& Blacks & $2(4 \%)$ & $7(18 \%)$ & $5(10 \%)$ & $5(10 \%)$ & $4(9 \%)$ \\
& Total & 47 & 40 & 48 & 50 & 43 \\
Super Rugby & Whites & $126(81 \%)$ & $123(78 \%)$ & $125(79 \%)$ & $138(80 \%)$ & $136(82 \%)$ \\
& Coloured & $23(15 \%)$ & $22(14 \%)$ & $22(14 \%)$ & $20(12 \%)$ & $21(13 \%)$ \\
& Blacks & $7(4 \%)$ & $12(8 \%)$ & $12(8 \%)$ & $14(8 \%)$ & $9(5 \%)$ \\
Currie Cup & Total & 156 & 157 & 159 & 172 & 166 \\
& Whites & $371(72 \%)$ & $373(70 \%)$ & $363(71 \%)$ & $371(74 \%)$ & $375(74 \%)$ \\
Vodacom & Coloured & $90(18 \%)$ & $101(19 \%)$ & $84(17 \%)$ & $72(14 \%)$ & $80(16 \%)$ \\
& Blacks & $51(10 \%)$ & $56(11 \%)$ & $62(12 \%)$ & $58(12 \%)$ & $52(10 \%)$ \\
& Total & 512 & 530 & 509 & 501 & 507 \\
Whites & $323(70 \%)$ & $313(65 \%)$ & $323(70 \%)$ & $348(71 \%)$ & $381(73 \%)$ \\
& Coloured & $82(18 \%)$ & $109(23 \%)$ & $85(18 \%)$ & $85(17 \%)$ & $84(16 \%)$ \\
& Blacks & $55(12 \%)$ & $57(12 \%)$ & $56(12 \%)$ & $59(12 \%)$ & $59(11 \%)$
\end{tabular}

Table 2. Total playing time (minutes) and (\%) of white, coloured and black rugby players for the Springboks, Super Rugby, Currie Cup and Vodacom teams, $2007-2011$

\begin{tabular}{|c|c|c|c|c|c|c|}
\hline & & 2007 & 2008 & 2009 & 2010 & 2011 \\
\hline \multirow[t]{4}{*}{ Springboks } & Whites & $13504(82 \%)$ & 9967 (64\%) & $12256(73 \%)$ & $12666(71 \%)$ & $8321(77 \%)$ \\
\hline & Coloured & $2833(17 \%)$ & $3965(26 \%)$ & $2861(17 \%)$ & $4361(24 \%)$ & $1863(17 \%)$ \\
\hline & Blacks & $212(1 \%)$ & $1627(11 \%)$ & $1596(10 \%)$ & $924 \quad(5 \%)$ & $572(5 \%)$ \\
\hline & Total & 16549 & 15559 & 16713 & 17951 & 10756 \\
\hline \multirow[t]{4}{*}{ Super Rugby } & Whites & $67297(82 \%)$ & 60217 (78\%) & $61616(77 \%)$ & $65685(82 \%)$ & $78773(81 \%)$ \\
\hline & Coloured & $11781(14 \%)$ & $10325(13 \%)$ & $10427(13 \%)$ & $9242(12 \%)$ & $13483(14 \%)$ \\
\hline & Blacks & $2759(3 \%)$ & $6484 \quad(8 \%)$ & $8256(10 \%)$ & $5300(7 \%)$ & $5572 \quad(6 \%)$ \\
\hline & Total & 81837 & 77026 & 80299 & 80227 & 97828 \\
\hline \multirow[t]{4}{*}{ Currie Cup } & Whites & $160039(76 \%)$ & $162578(72 \%)$ & $152614(71 \%)$ & $157972(76 \%)$ & $168912(77 \%)$ \\
\hline & Coloured & $33255(16 \%)$ & $40660(18 \%)$ & $37885(18 \%)$ & $30252(15 \%)$ & 30745 (14\%) \\
\hline & Blacks & $17689(8 \%)$ & $21602(10 \%)$ & $23370(11 \%)$ & $18515(9 \%)$ & $18607 \quad(9 \%)$ \\
\hline & Total & 210983 & 224840 & 213869 & 206739 & 218264 \\
\hline \multirow[t]{4}{*}{ Vodacom } & Whites & $87936(74 \%)$ & 87977 (67\%) & $80421(69 \%)$ & $92043(69 \%)$ & $101568(71 \%)$ \\
\hline & Coloured & $17613(15 \%)$ & $29506(22 \%)$ & 21456 (19\%) & 22595 (17\%) & $25832(18 \%)$ \\
\hline & Blacks & $12813(11 \%)$ & $14730(11 \%)$ & $14038(12 \%)$ & $17971(14 \%)$ & $16047(11 \%)$ \\
\hline & Total & 118362 & 132213 & 115915 & 132609 & 143447 \\
\hline
\end{tabular}

assumed that the number of players are represented appropriately in terms of expected playing time. When the data point is below the line of unity it suggests that according to the total number of players, there is an under-representation in terms of playing time (i.e. this would represent a scenario where players are selected to meet quotas). In contrast, if the data point lies above the line, then the players are playing more than expected (to compensate for players in the team who are playing less than expected). Using this logic the data are 
summarised in Table 3, showing whether there was overplaying $(\uparrow)$, underplaying $(\downarrow)$ or expected playing time for the number of players $(\approx)$. A margin of error of $1 \%$ was accepted in the interpretation.

Out of the 60 possible situations (5 years X 12 categories per year), there were 30 situations $(50 \%)$ where the playing time matched the number of players $(\approx)$ (Table 3 ). In $25 \%$ of the cases the players were over-represented and in $25 \%$ of the cases they were under-represented. There were no obvious trends over time. Based on the ratio of number of players v. playing time, at the Springbok level the white players played more times than expected whereas the black players played less than expected for the number of players from 2007 to 2011. At the Vodacom level the white players played more than expected in 2007 and 2008 and played less than expected in 2010 and 2011, whereas the black players played more than expected in 2010 and the coloured players played more than expected at the 2011 tournament. The Super Rugby tournament had the most consistency between players and playing time for the different ethnic groups. Across all tournaments and years the white players were over-presented $17 \%$ of the cases, the coloured players $5 \%$ of the cases and the black players $3 \%$ of the cases. In a similar comparison of under-presentation the white players were under-represented $5 \%$ of the time whereas the coloured and black players were both under-represented in $10 \%$ of the cases.

\section{Discussion}

The first finding of this study was that there were major differences in playing times of the senior players at all four levels of play (Vodacom, Currie Cup, Super Rugby and Springboks). In many cases the white players played more than expected based on their numbers, compared with the coloured and black players. The only times the white players played less than expected, based on their numbers, was at the Vodacom level and once at the Super 14 level (2009). The next finding was that there were no clear changes in the patterns of the proportions of white, coloured and black players from 2007 - 2011, at all levels of competition with the white players continuing to be dominant followed by coloured and then black players.

These data show that the numerous specialised programmes that SARU have implemented since 1998 have not had the desired effects of transforming the game. The way in which these results are interpreted needs to be carefully considered. There is the temptation to immediately conclude that the lack of transformation is due to the type of programmes that have been offered, or the way they have been implemented. One should however consider the complexity of high-performance sport and the factors that influence it prior to making any conclusions. Digel (2002) describes how worldclass performance in any country is dependent on three pillars: 'The first one is society, in general, as a resource for the elite sport system. The second is the sporting system itself. The third pillar is the environment of the specific sports system as defining factor for world class performance. ${ }^{10}$ This suggests that it is clear that there are other hurdles that need to be overcome before the effects of the specialised programmes can be realised. For example, a recent study of over 10000 South African schoolchildren (6 - 13 years) showed that there were significant differences in fitness scores and morphology of children of different ethnic origins, with the white children generally being bigger and scoring higher in the fitness tests than the coloured and black children. ${ }^{11}$ These differences were largely eliminated when socio-economic status was controlled.

Talent needs to be developed in a structured way, starting at a young age and progressing with maturity. ${ }^{12}$ Therefore it is obvious that children starting off compromised, because of being raised in a low socioeconomic environment, will always have a competitive disadvantage as they grow and mature. ${ }^{13}$ Junior player development pathways in rugby, as implemented by Australia and New Zealand, recognise the importance of specific development at various ages for success in the game. ${ }^{14}$ These models emphasise the importance of creating an environment where children (6-12 years of age) have the ability to develop the various characteristics critical to sports performance. ${ }^{15}$ It follows that community clubs and schools need to follow a development model across all socioeconomic groups that allow for optimum development at a young age and reduce the developmental difference between ethnic groups, as they get older. Every stage of development has different factors that contribute to the skill acquisition that is required by a high-level adult player. One of the key factors in South African Rugby is the alignment and cooperation between the different organisations in which the game is played, such as schools, clubs, universities and provincial unions. All SARU's efforts at development may be ineffective if the work of these different organisations is not aligned. Furthermore, the Departments of Sport, Education and Health also have an important contribution to ensure that the disparities arising from differences in socioeconomic status and facilities are reduced.

\section{Conclusion}

In summary, the data from this study suggest that the specialised programmes designed to accelerate transformation by creating an enabling environment, are not having the desired effect. We have

\begin{tabular}{|c|c|c|c|c|c|c|c|c|c|c|c|c|}
\hline & \multicolumn{3}{|c|}{ Springboks } & \multicolumn{3}{|c|}{ Super Rugby } & \multicolumn{3}{|c|}{ Currie Cup } & \multicolumn{3}{|c|}{ Vodacom } \\
\hline & W & $\mathrm{C}$ & B & W & $\mathrm{C}$ & B & W & $\mathrm{C}$ & B & $\mathbf{W}$ & $\mathrm{C}$ & B \\
\hline 2007 & $\uparrow$ & $\downarrow$ & $\downarrow$ & $\approx$ & $\approx$ & $\approx$ & $\uparrow$ & $\downarrow$ & $\downarrow$ & $\uparrow$ & $\downarrow$ & $\approx$ \\
\hline 2008 & $\approx$ & $\uparrow$ & $\downarrow$ & $\approx$ & $\approx$ & $\approx$ & $\uparrow$ & $\approx$ & $\approx$ & $\uparrow$ & $\approx$ & $\approx$ \\
\hline 2009 & $\uparrow$ & $\downarrow$ & $\approx$ & $\downarrow$ & $\approx$ & $\uparrow$ & $\approx$ & $\approx$ & $\approx$ & $\approx$ & $\approx$ & $\approx$ \\
\hline 2010 & $\approx$ & $\uparrow$ & $\downarrow$ & $\uparrow$ & $\approx$ & $\approx$ & $\uparrow$ & $\approx$ & $\downarrow$ & $\downarrow$ & $\approx$ & $\uparrow$ \\
\hline 2011 & $\uparrow$ & $\downarrow$ & $\downarrow$ & $\approx$ & $\approx$ & $\approx$ & $\uparrow$ & $\downarrow$ & $\approx$ & $\downarrow$ & $\uparrow$ & $\approx$ \\
\hline
\end{tabular}




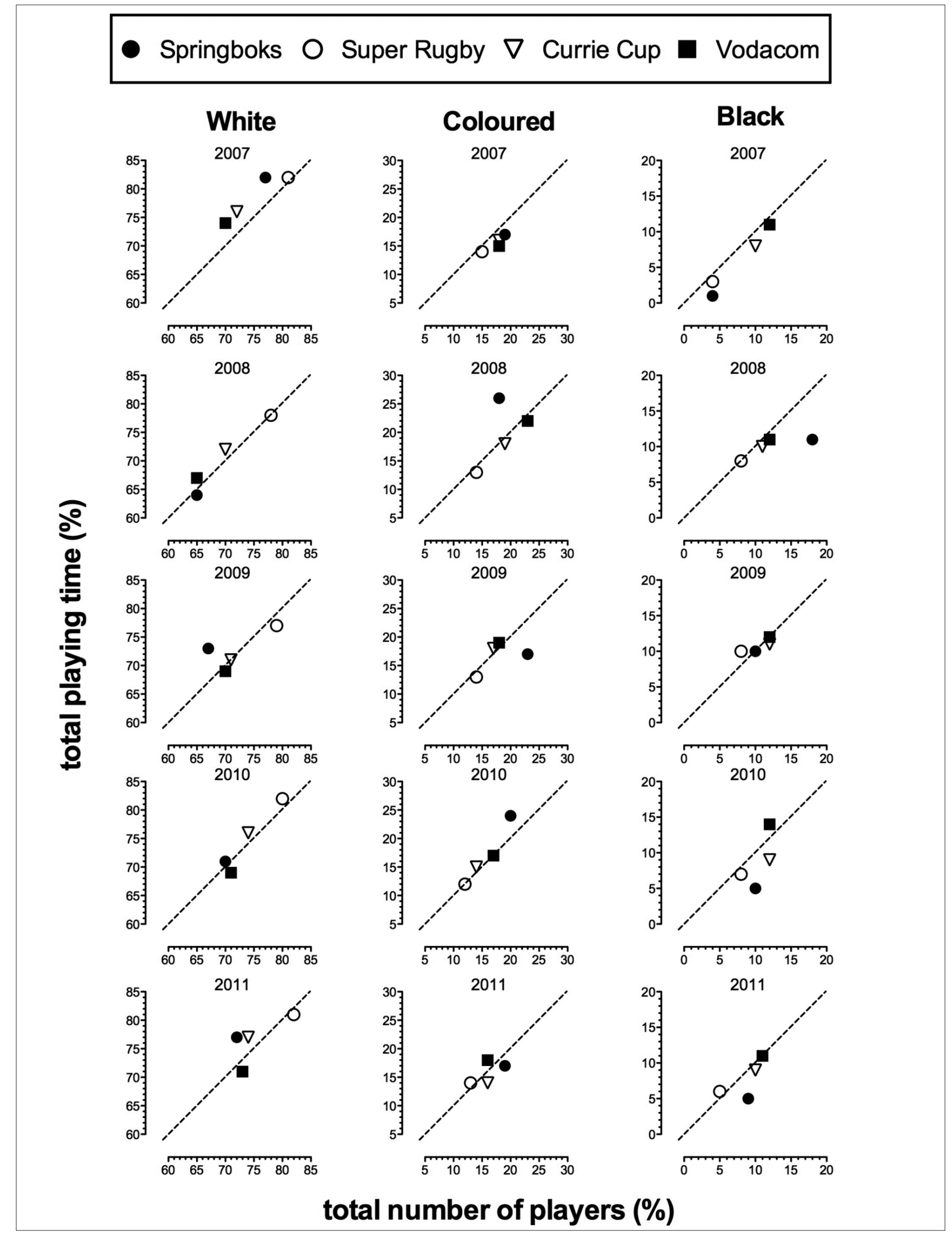

Fig. 1. Total number of players in each ethnic group expressed as a percentage of the number for that group $v$. the total playing time expressed as a percentage. 
highlighted the complex nature of transforming a sport which functions in the context of broader society and its structures. An example of a factor that will need to be addressed to improve the effectiveness of specialised programmes for youth and young adults is the disparity in body size and fitness of young children. This emphasises the importance of the different organs of society such as the state and sports organisations working closely together to ensure both high levels of participation and excellence. Until the fundamental inequalities in society are reduced, the specialised programmes designed to accelerate transformation are unlikely to achieve their desired outcome.

Finally, playing time should be collected on an on-going basis so that efficacy of the transformation projects within South African rugby can be measured. This approach is in accordance with the broader international debate regarding evidence-based policy making and practice in international sporting policies. ${ }^{16}$

\section{REFERENCES}

1. Heath D, Grieb E. SA Rugby Annual. $40^{\text {th }}$ ed. Cape Town: SARU \& MWP (Pty) Ltd; 2011.

2. Sulaiman S. Transformation policy for South African rugby: comparative perceptions. Cape Peninsula University of Technology theses and dissertations, 2006: 229.

3. Harmse J. Currie Cup too white - ABSA. 17-9-2010. http://www.sport24.co.za/ Rugby/ Currie-Cup-too-white-ABSA-20100917 (accessed 20 June 2011).

4. Durandt J. Coca-Cola Craven Week Project. Internal Report to SA Rugby, 12 August 2002.
5. South African Schools Rugby Association. Executive Meeting of the South African Schools Rugby Association, 19 February 2010.

6. Varsity Cup Competion Rules 2011. http:// www.varsitycup.co.za/index.php?option $=$ com_content\&view $=$ article $\&$ id $=3258$ (accessed 20 June 2011).

7. Meeting minutes between SA Rugby and provincial rugby presidents, 29 June 2006

8. South African Sport and Recreation, 2012; National Sport and Recreation Plan, 1-77, www.info.gov.za/view/DownloadFileAction?id=154620 (accessed 25 June 2012)

9. South African Sport and Recreation, 2012; Transformation Charter for South African Sport, 1-52, www.srsa.gov.za/MediaLib/Home/DocumentLibrary/ Transformation\%20 Charter\%20-\%20FINAL\%20Feb\%202012.pdf (accessed 25 June 2012)

10. Digel $\mathrm{H}$. The context of talent identification and promotion: A comparison of nations. New Studies in Athletics 2002;17:13-26.

11. Armstrong MEG, Lambert EV, Lambert MI. Physical fitness of South African primary school children, 6 to 13 years of age: Discovery Vitality Health of the Nation Study. Perceptual and Motor Skills, 2011;113(3):999-1016. [http://dx.doi. org/10.2466\%2F06.10.13.PMS.113.6.999-1016]

12. Vaeyens R, Lenoir M, Williams AM, Philippaerts RM. Talent identification and development programmes in sport: current models and future directions. Sports Med 2008;22(10):67-68.

13. Figueiredo AJ, Goncalves CE, Coelho E Silva MJ, Malina RM. Characteristics of youth soccer players who drop out, persist or move up. J Sports Sci 2009;27(9):883-891. [http://dx.doi.org/10.1080\%2F02640410902946469]

14. Lambert MI, Durandt J. Long-term player development in rugby - how are we doing in South Africa? S Afr J Sports Med 2010;22(10):67-68.

15. Bailey RP, Collins D, Ford PA, McNamara Á, Pearce G, Toms M. Participant development in sport: An academic literature review. Leeds: Sports Coach UK. Commissioned report for Sports Coach UK 2010;1-134.

16. Coalter F. A Wider Social Role for Sport: Who's Keeping the Score? London: Routledge, 2007. 